8-17-2016

\title{
Catastrophic Femoral Head-Stem Trunnion Dissociation Secondary to Corrosion.
}

\author{
Laura Matsen Ko \\ Orthopedic Physician Associates, Seattle, WA
}

Antonia F. Chen, MD, MBA

Rothman Institute, Thomas Jefferson University, Philadelphia, PA

Gregory K Deirmengian

Rothman Institute, Thomas Jefferson University, Philadelphia, PA

William J. Hozack MD

Rothman Institute at Thomas Jefferson University Hospital, Philadelphia, PA

Peter F. Sharkey

Rothman Institute \& Thomas Jefferson University Philadelphia, PA

Follow this and additional works at: https://jdc.jefferson.edu/rothman_institute

Part of the Orthopedics Commons

Let us know how access to this document benefits you

\section{Recommended Citation}

Matsen Ko, Laura; Chen, MD, MBA, Antonia F; Deirmengian, Gregory K; Hozack, William J. MD; and Sharkey, Peter F., "Catastrophic Femoral Head-Stem Trunnion Dissociation Secondary to Corrosion." (2016). Rothman Institute Faculty Papers. Paper 71.

https://jdc.jefferson.edu/rothman_institute/71

This Article is brought to you for free and open access by the Jefferson Digital Commons. The Jefferson Digital Commons is a service of Thomas Jefferson University's Center for Teaching and Learning (CTL). The Commons is a showcase for Jefferson books and journals, peer-reviewed scholarly publications, unique historical collections from the University archives, and teaching tools. The Jefferson Digital Commons allows researchers and interested readers anywhere in the world to learn about and keep up to date with Jefferson scholarship. This article has been accepted for inclusion in Rothman Institute Faculty Papers by an authorized administrator of the Jefferson Digital Commons. For more information, please contact: JeffersonDigitalCommons@jefferson.edu. 


\title{
Catastrophic Femoral Head-Stem Trunnion Dissociation Secondary to Corrosion
}

\author{
Laura Matsen Ko, MD, Antonia F. Chen, MD, MBA, Gregory K. Deirmengian, MD, William J. Hozack, MD, \\ and Peter F. Sharkey, MD \\ Investigation performed at The Rothman Institute at Thomas Jefferson University Hospital, Philadelphia, Pennsylvania
}

\begin{abstract}
Background: Modular femoral heads provide procedural enhancement by allowing accurate restoration of hip offset and limb-length equalization. However, corrosion may lead to adverse local tissue reactions. Severe trunnion corrosion can also lead to femoral head dissociation and catastrophic implant failure following primary total hip arthroplasty.
\end{abstract}

Methods: We describe 5 cases, from our institution, in which the femoral head became dissociated from the femoral stem trunnion secondary to severe corrosion. Possible causes are evaluated.

Results: Demographic commonalities among the 5 patients included a body mass index (BMI) of $\geq 30 \mathrm{~kg} / \mathrm{m}^{2}$ and male sex. All femoral heads were made of cobalt-chromium alloy and were larger-diameter implants $(\geq 36 \mathrm{~mm})$. Four of the 5 patients had a femoral head that increased the neck length above the default on a so-called standard head and 3 of the 5 had a stem with a $127^{\circ}$ neck-shaft angle.

Conclusions: Although dissociation of the femoral head from the femoral trunnion following total hip arthroplasty is exceedingly rare, the prevalence may increase with longer follow-up. The dissociation is likely related to multiple factors, including a BMI of $\geq 30 \mathrm{~kg} / \mathrm{m}^{2}$, male sex, and corrosion resulting from the use of a larger metal head with a neck length of greater than the default and a stem with high offset. It is critical that surgeons be able to recognize this mode of implant failure and appropriately prepare to remove the femoral component during revision surgery.

Level of Evidence: Therapeutic Level IV. See Instructions for Authors for a complete description of levels of evidence.

Peer Review: This article was reviewed by the Editor-in-Chief and one Deputy Editor, and it underwent blinded review by two or more outside experts. The Deputy Editor reviewed each revision of the article, and it underwent a final review by the Editor-in-Chief prior to publication. Final corrections and clarifications occurred during one or more exchanges between the author(s) and copyeditors.

$\mathrm{M}$ odular femoral heads provide procedural enhancement by allowing accurate restoration of hip offset and limb-length equalization, and they facilitate exposure should revision surgery be needed. However, corrosion can occur at modular interfaces, such as between the femoral head and trunnion during motion, and result in metal debris, inducing adverse local tissue reactions. Corrosion at modular interfaces is not well understood and is likely due to multiple factors. These include factors related to implant design, such as trunnion-taper angular mismatch, high-offset implants, trunnion diameter, neck angle, modular surface contact area, and dissimilar metals; patient factors, such as a high body mass index (BMI) or increased activity level; and surgical factors, such as damaged modular surfaces or inappropriate impaction forces ${ }^{1-4}$. Several authors have reported revision arthroplasty due to corrosion and adverse local tissue reactions ${ }^{5,6}$.

Severe trunnion corrosion, or deterioration of the femoral neck, can also lead to femoral head dissociation and catastrophic and sudden implant failure following primary total hip arthroplasty. However, unlike adverse local tissue reactions, this has been reported only rarely ${ }^{7}$. We describe 5 cases of dissociation of the femoral head from the trunnion secondary to severe corrosion, or loss of material from the femoral neck. Additionally, we evaluate demographic variables that place patients at higher risk for implant failure, including sex and BMI, as well as implant considerations. Finally, we emphasize the importance of recognizing the need for femoral stem revision in these situations.

Disclosure: There was no source of funding for this study. On the Disclosure of Potential Conflicts of Interest forms, which are provided with the online version of the article, one or more of the authors checked "yes" to indicate that the author had a relevant financial relationship in the biomedical arena outside the submitted work, including a relationship with the manufacturer of the device that is the subject of this article. 
The Journal of Bone \& Joint Surgery • JBjS. org Volume 98-A · Number 16 - August 17, 2016

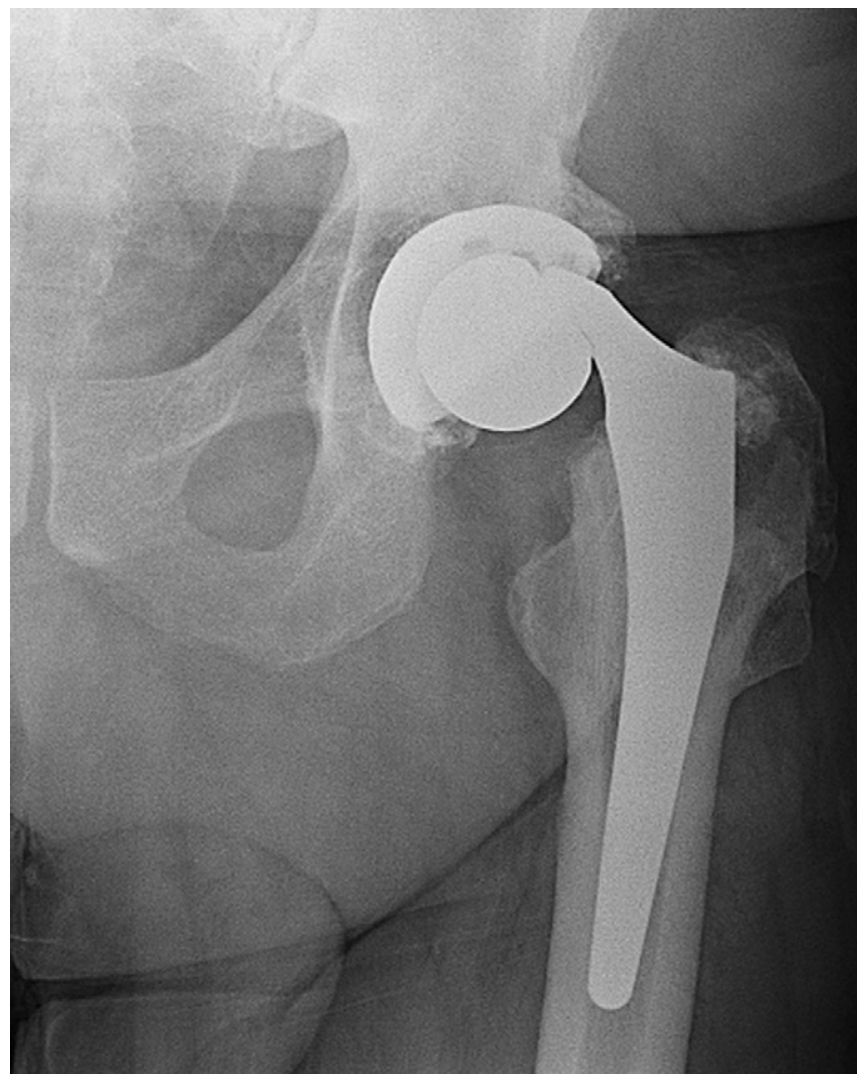

Fig. 1

Anteroposterior radiograph showing dissociation of the femoral head from the trunnion after a left total hip arthroplasty. Distortion of the femoral trunnion is visible. Evidence of osteolysis is present within the greater trochanter. There is no evidence of distal lucency or of loosening of the acetabular component.
Catastrophic Femoral Head-Stem Trunnion Dissociation SECONDARY TO CORROSION

\section{Case Reports}

CASE 1. A 59 -year-old man with a BMI of $37.5 \mathrm{~kg} / \mathrm{m}^{2}$ presented at 7 years following a total hip arthroplasty done with a $60-\mathrm{mm}$ Trident acetabular shell, a highly cross-linked polyethylene liner, a size $-40+4$ cobalt-chromium head, and a size-4.5 lateral-offset Accolade TMZF stem (Stryker Orthopaedics). Standard instrumentation was used to attach the metal femoral head, which was firmly impacted with a mallet and manually checked for adequate fixation on the trunnion. After 7 years of satisfactory function, the patient felt a sudden "pop" in the hip with associated pain and was unable to walk. Radiographs demonstrated dissociation of the femoral head from the stem trunnion (Fig. 1).

During the revision total hip arthroplasty, clear synovial fluid was aspirated after the surgeon opened the capsule and was sent for culture. The femoral head was within the acetabular liner, the femoral stem trunnion was dissociated from the head, and the trunnion was severely worn (Fig. 2). There was a small amount of dark metallic debris on the trunnion and the stem taper. The proximal part of the femur showed moderate osteolysis posteriorly, but the femoral stem was well fixed. Because of the severe trunnion wear, the femoral component was revised. There was no gross metallosis within the soft tissues. The acetabular liner was noted to be fractured in the posterior-superior region and was replaced. Multiple soft-tissue cultures were performed, and none were positive. A modular revision stem and a size- $36+0$ ceramic head were used to reconstruct the femur.

Postoperatively, the patient was immediately mobilized with weight-bearing as tolerated and discharged home on postoperative day 2.

CASE 2. A 63-year-old man with a BMI of $46.2 \mathrm{~kg} / \mathrm{m}^{2}$ presented to our clinic 6 years and 7 months after undergoing an index total hip arthroplasty at an outside facility. The acetabular

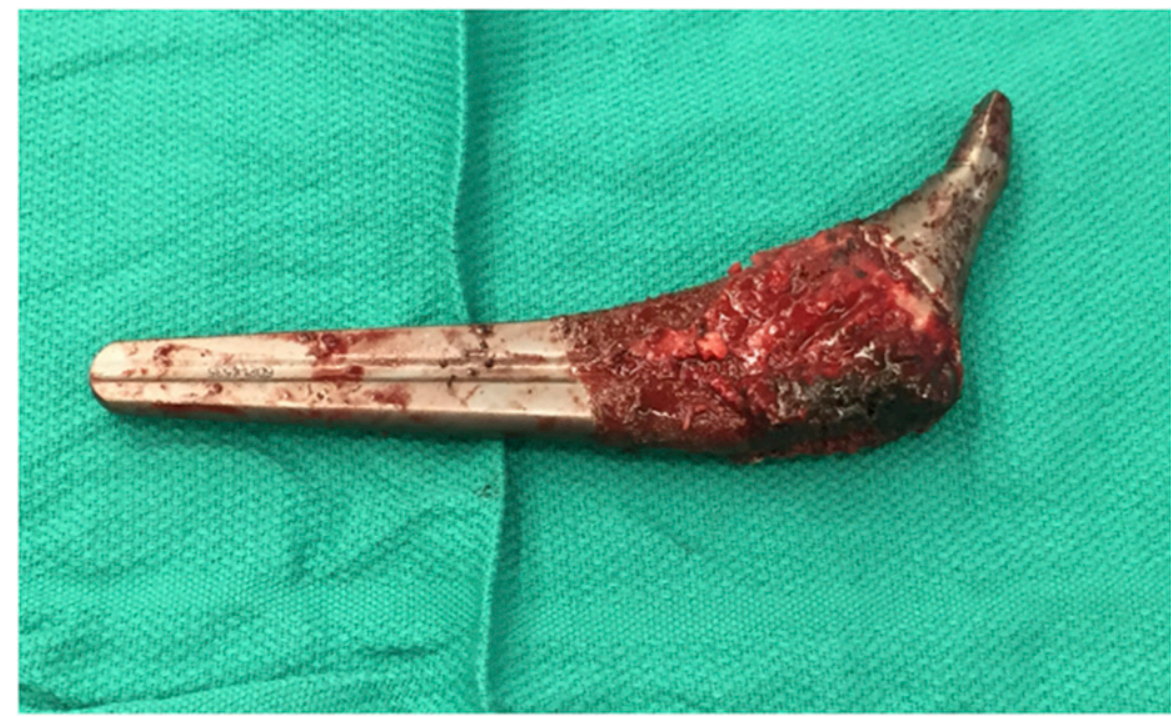

Severe deformation with weight-bearing and wear near the tip of the trunnion. 
1402

The Journal of Bone \& Joint Surgery $\cdot$ Jbjs.org Volume 98-A · Number 16 - August 17, 2016

Catastrophic Femoral Head-Stem Trunnion Dissociation SECONDARY TO CORROSION

\begin{tabular}{|c|c|c|c|c|c|}
\hline Date of revision & $12 / 2 / 14$ & $7 / 20 / 12$ & $9 / 25 / 13$ & $2 / 9 / 15$ & $1 / 15 / 15$ \\
\hline Time from index THA to revision $(y r+m o)$ & 7 & $6+7$ & $7+6$ & $7+4$ & $7+2$ \\
\hline Age at revision (yr) & 59 & 63 & 60 & 62 & 79 \\
\hline Height $(f t+$ in $[\mathrm{cm}])$ & $6+3(190.5)$ & $6+2(188.0)$ & $5+11(180.3)$ & $6+0(182.9)$ & $5+11(180.3)$ \\
\hline Weight (lb [kg]) & $300(136.1)$ & $360(163.3)$ & $217(98.4)$ & $240(108.9)$ & $182(82.6)$ \\
\hline $\mathrm{BMI}\left(\mathrm{kg} / \mathrm{m}^{2}\right)$ & 37.5 & 46.2 & 30 & 32.5 & 25.4 \\
\hline Stem type & Accolade I & Accolade I & Accolade I & Accolade I & Accolade I \\
\hline Stem size & 4.5 & 5 & 2 & 4.5 & 2.5 \\
\hline Cup type & Trident 60 & Trident 56 & Trident 54 & Trident 62 & Trident 56 \\
\hline
\end{tabular}

and femoral components were of the same design as those used in Case 1 but with a size-36+5 head. The patient had been doing well until he felt a pop in the hip, after which he used narcotics for pain and crutches for walking for 2 months. He then presented to our clinic. Radiographs demonstrated dissociation of the femoral head from the trunnion.

During the revision total hip arthroplasty, gross metallosis was encountered after opening of the capsule. The femoral head had disengaged from the trunnion, and the trunnion was severely damaged and could not support a new femoral head. The stem was well fixed, and extensive burring was required to remove the femoral component from the bone. The cup was exposed and noted to be stable, and a fresh acetabular liner was placed. Multiple soft-tissue cultures were performed, none of which were positive. A modular revision stem and a size-36+5 ceramic head were used to reconstruct the femur.

Postoperatively, the patient was immediately mobilized with weight-bearing as tolerated. He was discharged home on postoperative day 2. Motor and sensory sciatic neuropathy affecting the common peroneal branch recurred after the revision. It was managed with a brace, and there was little improvement at the 2-year follow-up examination.

CASE 3. A 60-year-old man with a BMI of $30 \mathrm{~kg} / \mathrm{m}^{2}$ presented with severe hip pain and difficulty walking 7.5 years after a total hip arthroplasty. The arthroplasty had been done with components of the same design as used in Cases 1 and 2, with a shell size of $54 \mathrm{~mm}$, a size- $36+5$ head, and a standard offset stem. The femoral head fixation had been manually checked after firm impaction with a head impactor. Radiographs made at 7.5 years confirmed dissociation of the femoral head.

During revision total hip arthroplasty, black corrosion material, consistent with metal wear debris, extruded after the capsule was opened. The head was separated from the trunnion, with severe trunnion damage. The acetabular component was exposed first, and the polyethylene was removed. The cup was deemed to be in an appropriate position, and thus a new liner was impacted into place. Because of the trunnion damage, it was necessary to remove the femoral component, which required an extended femoral trochanteric osteotomy. A modular revision stem and a size- $36+2.5$ ceramic head were used to reconstruct the femur.

Postoperatively, the patient was immediately mobilized with protected weight-bearing and discharged home on postoperative day 2. He was doing well at the time of follow-up 1.5 years postoperatively.

CASE 4. A 62-year-old man with a BMI of $32.5 \mathrm{~kg} / \mathrm{m}^{2}$ presented 7 years and 4 months after the index total hip arthroplasty, which had been done with components of the same design as in the previous cases. This patient had a $62-\mathrm{mm}$ shell, a size $40+0$ head, and a standard offset stem. The head initially had been firmly attached to the trunnion, as per the senior surgeon's usual protocol. The patient had difficulty walking, rising from a chair, and getting in and out of an automobile. Radiographs demonstrated gross trunnion failure.

On opening of the capsule at the revision total hip arthroplasty, it was evident that the femoral trunnion had completely worn down and the femoral head had dislodged from the trunnion. There was black staining throughout the tissues. The acetabulum was first exposed, and the liner was removed. The cup was noted to be stable and well positioned, and thus was left in place. A new liner was placed. The femoral component was then exposed and, given that it was well fixed, we proceeded with an extended trochanteric osteotomy to remove it. A modular revision stem and a size- $36+5$ ceramic head were used to reconstruct the femur. 
The Journal of Bone \& Joint Surgery • JBjS. org Volume 98-A · Number 16 - August 17, 2016
Catastrophic Femoral Head-Stem Trunnion Dissociation SECONDARY TO CORROSION
Postoperatively, the patient was immediately mobilized with protected weight-bearing and discharged home on postoperative day 2 .

CASE 5. A 79-year-old man with a BMI of $25.4 \mathrm{~kg} / \mathrm{m}^{2}$ presented to our clinic 7 years following an index total hip arthroplasty with components of the same design as used in the other 4 cases. In this patient, a 56- $\mathrm{mm}$ shell, a size- $36+5$ head, and a lateral offset stem were used. The patient was doing well until 2 weeks prior to presentation, at which time clinical examination and radiographs confirmed failure of the index arthroplasty, with femoral head dissociation. The patient underwent revision surgery at an outside facility and we were unable to obtain the operative notes for that procedure, but the case is included because of the similarity in the pattern of catastrophic trunnion wear.

Demographic data for all cases are shown in Table I.

\section{Discussion}

$\mathrm{W}$ e report 5 cases of catastrophic failure of modular total hip arthroplasty related to severe trunnion corrosion and wear-a prevalence of $0.052 \%(5 / 9,688)$ in our patient population who received the Accolade TMZF stem. The denominator was based on the number of stems implanted from 2000 to 2011 at our institution. However, the true denominator is not known as the number of patients with the characteristics associated with catastrophic trunnion dissociation (e.g., higher activity level, male sex, higher BMI, an implant combination identical to that in our series, the same duration of follow-up as in our series) and patients lost to follow-up who underwent revision elsewhere is not known. We are aware of only 2 similar cases reported in the literature. Banerjee et al. recently described a series of patients with unusual trunnion complications ${ }^{7}$. One was a 67-year-old man with a BMI of $40 \mathrm{~kg} / \mathrm{m}^{2}$ who had undergone total hip arthroplasty with an ML taper (Zimmer), an extended offset taper stem, and a size-32+4 cobalt-chromium skirted femoral head. Eight years after the total hip arthroplasty, the patient presented with dissociation of the femoral head from the trunnion. Another patient in that series, a 60 -year-old man with a BMI of $30 \mathrm{~kg} / \mathrm{m}^{2}$, also presented with dissociation of the femoral head from the trunnion, 7 years after a total hip arthroplasty with an Accolade TMZF stem (Stryker Orthopaedics) and a size- $40+4$ cobalt-chromium femoral head.

Demographic commonalities among the 5 patients in our series included male sex, a height of $>5 \mathrm{ft} 10$ in $(177.8 \mathrm{~cm})$ (range, $5 \mathrm{ft} 11 \mathrm{in}[180.3 \mathrm{~cm}]$ to $6 \mathrm{ft} 3$ in $[190.5 \mathrm{~cm}]$ ), and a weight of $>180 \mathrm{lb}(81.6 \mathrm{~kg}$ ) (mean, $260 \mathrm{lb}$ [117.9 kg]; range, $182 \mathrm{lb}$ [82.6 kg] to $360 \mathrm{lb}[163.3 \mathrm{~kg}])$. Greater load can lead to a greater force on the femoral head-trunnion interface, and this has been shown to accelerate wear and corrosion ${ }^{8}$. Increases in the size of Accolade TMZF stems are associated with increases in neck length and offset. A standard offset stem ranges from size 0 to size 8 , with the neck length increasing by $10 \mathrm{~mm}$ (from $30 \mathrm{~mm}$ for size 0 to $40 \mathrm{~mm}$ for size 8) and offset increasing by $16 \mathrm{~mm}$ (from $33 \mathrm{~mm}$ for size 0 to $49 \mathrm{~mm}$ for size 8$)^{9}$. The primary hip stems used in this series ranged from size 2 to size 5 (mean, 3.7) and are considered mid-range stems.
Other commonalities in this small patient group may have increased the potential for corrosion. Most importantly, all femoral heads were made of cobalt-chromium alloy, which, when combined with a titanium trunnion, can lead to galvanic corrosion and weakening of the trunnion interface ${ }^{8}$.

In this case series, all femoral heads used for the index total hip arthroplasty were large in diameter, either size $36 \mathrm{~mm}$ or size $40 \mathrm{~mm}$, and 3 of the 5 patients had an increased offset. Large femoral heads and high-offset stems have been shown to increase fretting corrosion at the femoral head interface. Peak trunnion stresses and trunnion micromotion increase substantially with increased femoral head diameter ${ }^{9-11}$. Both laboratory and retrieval studies have shown that a large head increases the frictional torque and accelerates wear ${ }^{4,12,13}$.

All patients in our series underwent total hip arthroplasty with an Accolade TMZF stem, which was the most commonly implanted stem at our institution. The Accolade TMZF stem is composed of beta titanium (titanium, molybdenum, zirconium, and fluoride), a titanium alloy with $25 \%$ greater flexibility compared with the standard Ti-6Al-4V alloy ${ }^{14}$. Because of this lower modulus of elasticity, it is possible that the normal forces of gait increase bending of the titanium trunnion within the cobalt-chromium femoral head. Possible factors related to catastrophic failure are described in Figure 3.

There were also commonalities related to surgical technique. In 4 patients, the surgeon chose a femoral head that further increased neck length and 3 of the stems had a design specifically intended to increase offset $\left(127^{\circ}\right.$ versus $132^{\circ}$ neck-shaft angle). The data concerning fretting corrosion rates with regard to femoral

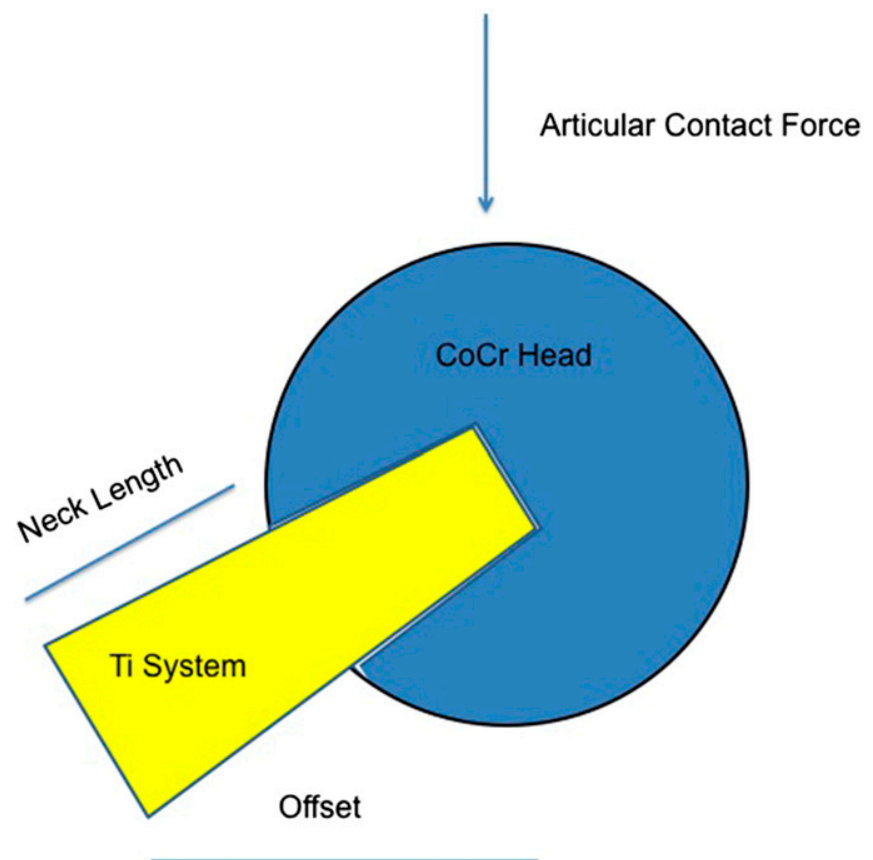

Fig. 3

Trunnion wear is likely related to a number of factors, including BMI, number of cycles placed on the hip, femoral head size, offset, neck length, and stem design. 
The Journal of Bone \& Joint Surgery - jbjs.org Volume 98-A · Number 16 - August 17, 2016
Catastrophic Femoral Head-Stem Trunnion Dissociation SECONDARY TO CORROSION neck length and offset of the femoral stem are mixed. One study demonstrated no increase in fretting with extended offset femoral stems ${ }^{15}$. Another study showed increased evidence of fretting damage but mixed statistical results regarding quantifiable corrosion with extended offset femoral stems ${ }^{1}$.

While severe femoral head-stem trunnion dissociation is troubling, it should be noted that this stem was available from 2001 to 2011 and reports of failure clustered around 7 to 7.5 years after surgery. We would expect more failures of this stem if this were a universal problem. However, precautions can be taken, such as checking serum cobalt and chromium levels in high-risk patients-i.e., those who are young, are active, have a higher BMI, are male, and have a $\geq 36 \mathrm{~mm}$-diameter femoral head. These levels should definitely be checked in symptomatic patients, and patients with elevated metal-ion levels should undergo a metal artifact reduction sequence (MARS) magnetic resonance imaging (MRI) scan. Periodic radiographic follow-up every 3 to 4 years may be important for diagnosing at-risk patients prior to catastrophic failure, as early wear of the trunnion may be seen on radiographs prior to catastrophic failure. Asymptomatic patients with normal cobalt-chromium levels may not benefit from prophylactic surgery, but those with impending failure (e.g., a narrowed trunnion) may benefit from augmentation of the femoral trunnion or placement of a sleeve on it, or from replacing the femoral head with one of a smaller size $(32 \mathrm{~mm})$.

Our study had limitations. Because we studied an uncommon phenomenon, the sample size was small and the correlation of factors such as BMI and male sex with catastrophic femoral head-trunnion dissociation should be interpreted in light of that limitation. Implants were not sent for further evaluation after explantation, and there was no pathological evaluation of the surrounding tissue. Additionally, there were no measurements of serum cobalt and chromium metal-ion levels, which would have strengthened our findings. Finally, since this was a retrospective study of femoral head-trunnion dissociation, we do not specifically know how the femoral head was impacted onto the trunnion. However, in the other primary total hip arthroplasties performed at our institution, the femoral head was impacted onto the trunnion in the same manner as used for primary total hip arthroplasties performed during the same time frame that did undergo catastrophic failure.

In summary, we present a unique case series in which the femoral head became dissociated from the femoral trunnion following total hip arthroplasty. While this complication is exceedingly rare, its prevalence may increase with longer follow-up. Since we do not have accurate knowledge of the total number of cases from which these 5 cases were derived, any attempt to implicate one aspect of patient demographics, component design, or surgical technique would be unwise. We think that the combination of patient demographics (heavy, tall, and male), component factors (a large-diameter cobalt-chromium femoral head and a stem made of flexible titanium alloy), and surgical technique (high offset) may all work together to cause this catastrophic event. It is critical that surgeons be able to recognize this mode of implant failure and appropriately prepare to remove the femoral component during revision surgery.

Laura Matsen Ko, $\mathrm{MD}^{1}$

Antonia F. Chen, MD, MBA ${ }^{2}$

Gregory K. Deirmengian, $\mathrm{MD}^{2}$

William J. Hozack, $\mathrm{MD}^{2}$

Peter F. Sharkey, $\mathrm{MD}^{2}$

${ }^{1}$ Orthopedic Physician Associates, Seattle, Washington

${ }^{2}$ The Rothman Institute at Thomas Jefferson University Hospital, Philadelphia, Pennsylvania

E-mail address for P.F. Sharkey: peter.sharkey@rothmaninstitute.com

\section{References}

1. Gilbert JL, Mehta M, Pinder B. Fretting crevice corrosion of stainless steel stem-CoCr femoral head connections: comparisons of materials, initial moisture, and offset length. J Biomed Mater Res B Appl Biomater. 2009 Jan; 88(1):162-73.

2. Goldberg JR, Gilbert JL. In vitro corrosion testing of modular hip tapers. J Biomed Mater Res B Appl Biomater. 2003 Feb 15;64(2):78-93.

3. Jacobs JJ, Cooper HJ, Urban RM, Wixson RL, Della Valle CJ. What do we know about taper corrosion in total hip arthroplasty? J Arthroplasty. 2014 Apr;29(4): 668-9. Epub 2014 Feb 18.

4. Goldberg JR, Gilbert JL, Jacobs JJ, Bauer TW, Paprosky W, Leurgans S. A multicenter retrieval study of the taper interfaces of modular hip prostheses. Clin Orthop Relat Res. 2002 Aug;401:149-61.

5. Cooper HJ, Della Valle CJ, Berger RA, Tetreault M, Paprosky WG, Sporer SM, Jacobs JJ. Corrosion at the head-neck taper as a cause for adverse local tissue reactions after total hip arthroplasty. J Bone Joint Surg Am. 2012 Sep 19;94(18): 1655-61.

6. Kiran M, Boscainos PJ. Adverse reactions to metal debris in metal-on-polyethylene total hip arthroplasty using a titanium-molybdenum-zirconium-iron alloy stem. J Arthroplasty. 2015 Feb;30(2):277-81. Epub 2014 Oct 30.

7. Banerjee S, Cherian JJ, Bono JV, Kurtz SM, Geesink R, Meneghini RM, Delanois RE, Mont MA. Gross trunnion failure after primary total hip arthroplasty. J Arthroplasty. 2015 Apr;30(4):641-8. Epub 2014 Nov 26.
8. Panagiotidou A, Meswania J, Osman K, Bolland B, Latham J, Skinner J, Haddad FS, Hart A, Blunn G. The effect of frictional torque and bending moment on corrosion at the taper interface: an in vitro study. Bone Joint J. 2015 Apr;97-B(4):463-72.

9. Dyrkacz RM, Brandt JM, Ojo OA, Turgeon TR, Wyss UP. The influence of head size on corrosion and fretting behaviour at the head-neck interface of artificial hip joints. J Arthroplasty. 2013 Jun;28(6):1036-40. Epub 2013 Mar 23.

10. Elkins JM, Callaghan JJ, Brown TD. Stability and trunnion wear potential in largediameter metal-on-metal total hips: a finite element analysis. Clin Orthop Relat Res. 2014 Feb;472(2):529-42.

11. Pastides PS, Dodd M, Sarraf KM, Willis-Owen CA. Trunnionosis: a pain in the neck. World J Orthop. 2013;4(4):161-6. Epub 2013 Oct 18.

12. Howie DW, Holubowycz OT, Middleton R; Large Articulation Study Group. Large femoral heads decrease the incidence of dislocation after total hip arthroplasty: a randomized controlled trial. J Bone Joint Surg Am. 2012 Jun 20;94(12):1095-102.

13. Cooper $\mathrm{HJ}$, Della Valle $\mathrm{CJ}$. Large diameter femoral heads: is bigger always better? Bone Joint J. 2014 Nov;96-B(11)(Suppl A):23-6.

14. Casper DS, Kim GK, Restrepo C, Parvizi J, Rothman RH. Primary total hip arthroplasty with an uncemented femoral component five- to nine-year results. J Arthroplasty. 2011 Sep;26(6):838-41. Epub 2011 Apr 5.

15. Nassif NA, Nawabi DH, Stoner K, Elpers M, Wright T, Padgett DE. Taper design affects failure of large-head metal-on-metal total hip replacements. Clin Orthop Relat Res. 2014 Feb;472(2):564-71. 